\title{
ALFABETIZAÇÃO CIENTÍFICA: UM ESTUDO BIBLIOGRÁFICO ACERCA DOS TRABALHOS PRODUZIDOS NO ENSINO DE QUÍMICA NA REVISTA QNESC
}

\author{
Apresentação: Comunicação Oral \\ Marcel Vila Nova de Jesus ${ }^{1}$; Thiago Freire Do Emery²; Lucas Queiroz Dos Santos ${ }^{3}$; Artur \\ Torres de Araújo ${ }^{4}$; Eliemerson de Souza Sales ${ }^{5}$
}

\begin{abstract}
Resumo
O ensino de ciências passou por diversas transformações e sofreu várias influências, e considerando a importância da Alfabetização Científica nesse processo de ensino, buscou-se investigar se os trabalhos produzidos na área, especificamente no ensino de química tem apresentado dentro de seu escopo estrutural os objetivos da Alfabetização Científica. Para tanto este estudo se refere a uma pesquisa bibliográfica, apresentando uma abordagem qualitativa. Foram analisados 24 artigos da Revista Química Nova na Escola - QNEsc, especificamente na sessão "Química e Sociedade", do volume 29 ao volume 38. Utilizamos como categorias de análise as finalidades da Alfabetização Científica de acordo com os estudos de Milaré (2008). A escolha da revista se justifica pelo fato de ter se tornado um instrumento de formação continuada para professores de química no sentido de vir a ser um material que auxilia os professores de química na construção de metodologias que ajudem no processo de ensino e aprendizagem em química. A escolha da sessão se justifica pelo fato de estar voltada ao diálogo entre os conhecimentos científicos e as questões sociais. Por fim, destacamos que a alfabetização científica não tem como finalidade a formação de cientistas, e sim, em colaborar no desenvolvimento social por meio da conscientização da população acerca do conhecimento científico, importante na resolução de problemas e discussões através de temas comuns no cotidiano. Também ressaltamos que, os trabalhos analisados trazem de maneira clara e objetiva uma perspectiva inovadora para o desenvolvimento do elo entre ciências e sociedade, destacando temas corriqueiros no dia-a-dia para explicar determinado fenômeno, procedimento e processo levando o indivíduo a um estágio de entendimento e reflexão no âmbito das experiências vividas diariamente.
\end{abstract}

Palavras-Chave: Alfabetização Científica, Ensino de Ciências, Ensino de Química.

\footnotetext{
${ }^{1}$ Licenciatura em Química, Universidade Federal de Pernambuco, marcelvilanova@gmail.com

${ }^{2}$ Licenciatura em Química, Universidade Federal de Pernambuco, freire.or.thiago@gmail.com

${ }^{3}$ Licenciatura em Química, Universidade Federal de Pernambuco, Iqdossantos@gmail.com

${ }^{4}$ Doutorando pelo Programa de Pós-Graduação em Ensino das Ciências - PPGEC/UFRPE e Professor de Educação em Química da Universidade Federal de Pernambuco - UFPE, arturdesume@hotmail.com

${ }^{5}$ Mestrando do Programa de Pós-Graduação em Educação em Ciências e Matemática - PPGECM/UFPE e Professor de Educação em Química da Universidade Federal de Pernambuco - UFPE, eliemersonsales@gmail.com
} 


\section{Introdução}

No que se refere a Alfabetização Científica (AC) para o contexto do ensino de ciências/química, percebe-se que um dos grandes desafios de desenvolvimento de práticas didático-pedagógicas está no entendimento do professor acerca dos fundamentos da AC.

Partindo desse contexto, encontramos diversos estudos que fazem referência a “Alfabetização Científica” (SASSERON E CARVALHO, 2008; DELIZOICOV, 2001; FILHO, SEPINI E ALONSO, 2013; VIECHENESKI, 2011; SASSERON E CARVALHO, 2011; CHASSOT, 2003). Esse termo tem sido usado em diversos estudos como os mencionados acima, como um dos principais objetivos do ensino de ciências, senão o mais importante, dado a ênfase dos estudos nesta área, embora dada a diversidade de termo como: Alfabetización Científica, Scientific Literacy, Alphabétisation Scientifique, Letramento Científico, Enculturação Científica.

Segundo Sasseron e Carvalho (2008, p. 334),

Podemos perceber que no cerne das discussões levantadas pelos pesquisadores que usam um termo ou outro estão as mesmas preocupações com o ensino de Ciências, ou seja, motivos que guiam o planejamento deste ensino para a construção de benefícios práticos para as pessoas, a sociedade e o meio-ambiente.

Diante do exposto, dialogamos com as ideias das autoras supracitadas no que concerne aos objetivos da Alfabetização Científica. Ideias que dialogam com a concepção de alfabetização trazida por Paulo Freire que considera o processo de alfabetização como sendo mais que um domínio psicológico e mecânico de técnicas, mas sim, no sentido consciente, implicando na autoformação, implicando na atuação do homem sobre o seu contexto a partir do processo de alfabetização (FREIRE, 1980).

Nessa direção, visto que o ensino de ciências passou por diversas transformações e sofreu várias influências, e considerando a importância da Alfabetização Científica nesse processo de ensino, buscou-se investigar se os trabalhos produzidos na área, especificamente no ensino de química tem apresentado dentro de seu escopo estrutural os objetivos da Alfabetização Científica. Ressaltamos que, no capítulo que se segue apresentamos uma discussão mais aprofundada acerca do que vem a ser a Alfabetização Científica na perspectiva defendida neste estudo.

\section{Fundamentação Teórica}

O nosso referencial se sustenta a partir dos estudos de Sasseron e Carvalho (2011) e também nos estudos de Milaré (2008) que apresentam discussões referente a Alfabetização Científica (AC). No entanto, convidamos ao diálogo no decorrer do texto, os estudos de Furió 
(2001), Lorenzeti e Delizoicov (2003), Fourez et al (1997), dentre outros.

A Alfabetização científica para Furió (2001) é definida como sendo as,

[...] possibilidades de que a grande maioria da população disponha de conhecimentos científicos e tecnológicos necessários para se desenvolver na vida diária, ajudar a resolver os problemas e as necessidades de saúde e sobrevivência básica, tomar consciência das complexas relações entre ciência e sociedade (FURIÓ et al, 2001, p. 365).

Neste contexto a AC surgirá como solução aos problemas do cotidiano do cidadão, através dos conhecimentos adquiridos pode-se por exemplo criar hábitos alimentares saudáveis e assim prevenir possíveis doenças, poder dirimir acerca do uso constante de repelentes e possíveis problemas como o desenvolvimento futuro de insetos que possuem uma resistência a estes produtos, discutir sobre o uso dos agrotóxicos e os seus efeitos sobre o meio ambiente como um todo, poder discutir e conscientizar a população sobre a construção de uma barragem em uma área de reserva ecológica.

Hurd (1998) aborda uma definição de AC que está na mesma linha de pensamento de Furió (2001), onde conceitua como sendo a criação e a aplicação da ciência na vida do homem e que ocasione transformações revolucionárias na ciência com dimensões na democracia, na necessidade de adaptação do ser humano e no desenvolvimento social. Nesse sentido, o ensino de ciências terá por finalidade colaborar para a realização destes objetivos através da compreensão de valores, conhecimentos e procedimentos que façam com que o indivíduo tome certar decisões e perceba tanto a parte positiva como a negativa e as suas limitações.

É importante ressaltar que, um estudante alfabetizado cientificamente possui um conhecimento mínimo necessário para avaliar os avanços tecnológicos e científicos e suas implicações no meio ambiente a na sociedade (SOLBES, 2004). Também, torna-se relevante destacar que, uma concepção muito errônea que se tem é de que a AC tem por intuito fazer com que um indivíduo domine a ciência, ou seja, um cientista. Lorenzeti e Delizoicov (2003) debate sobre isto, argumentando que, um indivíduo alfabetizado cientificamente não dominará a ciência, fato este que nem mesmo os cientistas a dominam.

Fourez (1994) discute as habilidades que são necessárias para classificar se um indivíduo é alfabetizado cientificamente. Entre elas estão o fato de reconhecer que existe um denominador limiar do uso da ciência e tecnologia para o bem-estar humano, visto que, muitas vezes um conhecimento científico pode ser usado de forma maléfica. Como exemplo podemos citar o caso do domínio da técnica de enriquecimento de material radioativo onde através disto foi possível criar uma bomba atômica e que com este mesmo conhecimento foi possível a criação de um método de obtenção de energia através de material radioativo (Usinas nucleares). 
Hurd (1998) comenta que as características de uma pessoa alfabetizada cientificamente não são ensinadas diretamente, mas estão embutidas no currículo escolar, em que os alunos são chamados a solucionar problemas, a realizar investigações, a desenvolver projetos em laboratório de apoio e experiências de campo. Pode-se ver que estas atividades são compreendidas como preparação para o exercício da cidadania e não para a formação de cientistas. Outro aspecto que é bastante discutido e acerca do currículo escolar que seria necessário para o processo de ensino-aprendizagem que contribuísse para a formação do estudante.

Segundo Shen (1975), existem três noções de alfabetização científica, sendo estas nomeadas de Alfabetização Científica - AC prática, cívica e cultural. As diferenças entre elas estão nos seus objetivos. A AC-prática parte do pressuposto que grande parte da população vive em condições precárias e em específico com pouco conhecimento científico, ela surge para contribuir de forma positiva para o indivíduo que está nesta situação, tornando-o apto a solucionar de forma imediata problemas que afetam a sua vida, ou seja, é um tipo de conhecimento que pode ser usado imediatamente para melhorar os padrões de vida. Esta alfabetização está relacionada com as necessidades humanas básicas (saúde, habitação, alimentação, etc.).

Já a AC-Cívica tem por finalidade fazer com que o indivíduo seja mais atento para a ciência e os seus possíveis problemas, de maneira que os cientistas e os indivíduos de um modo geral possam tomar decisões mais bem instruídos sobre diversos problemas relacionados a ciência. Destaca-se que, a aquisição de um nível funcional de $\mathrm{AC}$ - Cívica será um esforço mais demorado do que a AC - Prática.

Por fim a $\mathrm{AC}$ - Cultural, que é definida como os aspectos relacionados à natureza da ciência e da tecnologia e curiosidades sobre o seu desenvolvimento. A AC-cultural é motivada por um desejo de saber algo sobre ciência. Esta não resolve nenhum problema prático de forma direta, entretanto contribui para abrir caminhos para a ampliação entre as culturas humanísticas e científicas.

Outro objetivo da Alfabetização Científica que é abordada por outros autores ${ }^{6}$ é a que está relacionada ao aspecto econômico, profissional e político que estimula a formação de pessoas para atuar nesta área científica tendo por finalidade promover e manter o crescimento econômico do país (MILARÉ, 2008). Pode-se ver que os aspectos mostrados nos parágrafos anteriores em relação a Alfabetização Científica (Prática, Cultural, Cívica e

\footnotetext{
${ }^{6}$ Sobre isso, ver: (FOUREZ, 1997; POLINO, 2003).
} 
Econômica/Profissional/Política) tem por intuito o aprimoramento de habilidades que serão utilizadas pelos indivíduos, conforme o contexto e suas necessidades. Ou seja, a alfabetização científica não se resume apenas ao ambiente escolar, sendo continuamente adquiridas e aprimoradas. Estas dimensões estão relacionadas com a formação do cidadão.

Por fim, outro aspecto a ser destacado quando se trata de alfabetização científica, é que para que o ensino de ciências tenha por finalidade criar essa cultura cientifica nos estudantes, qualquer estratégia de ensino que tenha por finalidade algum dos objetivos da alfabetização científica, requer um professor bem preparado. Nesse sentido, os professores precisam ter uma sólida formação sobre a história da ciência, aspectos epistemológicos, sociológicos, tecnológicos, interdisciplinar, dentre outros, para que atinja aos objetivos da alfabetização científica (FOUREZ, 1997).

\section{Metodologia}

Este estudo se refere a uma pesquisa bibliográfica, apresentando uma abordagem qualitativa, que teve como objetivo investigar se os trabalhos produzidos na área de ensino de química têm apresentado dentro de seu escopo estrutural os objetivos da Alfabetização Científica.

Para tanto, delimitamos o nosso campo de investigação. Foram analisados 24 artigos da Revista Química Nova na Escola - QNEsc, especificamente na sessão “Química e Sociedade”, do volume 29 ao volume 38. A escolha da revista se justifica pelo fato de ter se tornado um instrumento de formação continuada para professores de química no sentido de vir a ser um material que auxilia os professores de química na construção de metodologias que ajudem no processo de ensino e aprendizagem em química. A escolha da sessão se justifica pelo fato de estar voltada ao diálogo entre os conhecimentos científicos e as questões sociais.

Nesse sentido, utilizamos as finalidades da alfabetização cientifica como categorias de análise de acordo com os estudos de Milaré (2008).

Outro fator analisado nos artigos, e de caráter complementar, foram os conteúdos de química necessário para a compreensão dos artigos analisados, uma vez que, é fundamental e essencial a relação do conteúdo de uma determinada ciência neste caso a química com os aspectos observados diariamente, levando o estudante a uma compreensão cientifica de diversos fenômenos.

\section{Resultados e Discussão}

Iniciamos essa sessão apresentando a tabela que se refere ao tema social encontrado nos 
trabalhos analisados e as categorias encontradas nos respectivos trabalhos.

\begin{tabular}{|c|c|c|c|c|c|}
\hline \multirow{2}{*}{$\begin{array}{l}\text { Trabalhos } \\
\text { Analisados }\end{array}$} & \multirow[t]{2}{*}{ Tema Social } & \multicolumn{4}{|c|}{ Finalidades da Alfabetização Científica } \\
\hline & & Prático & Cívico & Cultural & $\begin{array}{l}\text { Profissional/ } \\
\text { Econômico }\end{array}$ \\
\hline $\begin{array}{l}\text { Takahashi, } \\
\text { Martins e } \\
\text { Quadro } \\
(2008)\end{array}$ & Transgênicos & & & $\mathbf{X}$ & \\
\hline $\begin{array}{l}\text { Zuin, Ioriatti, } \\
\text { Matheus } \\
(2009)\end{array}$ & Águas Naturais & $\mathbf{X}$ & $\mathbf{X}$ & & \\
\hline $\begin{array}{l}\text { Santos e Silva } \\
(2009)\end{array}$ & Tênis & $\mathbf{X}$ & $\mathbf{X}$ & $\mathbf{X}$ & \\
\hline $\begin{array}{l}\text { Cangemi, } \\
\text { Santos e Neto } \\
(2009)\end{array}$ & Polímeros & $\mathbf{X}$ & $\mathbf{X}$ & $\mathbf{X}$ & \\
\hline $\begin{array}{l}\text { Matheus, } \\
\text { Machado e } \\
\text { Brasileiro } \\
(2009)\end{array}$ & $\begin{array}{l}\text { Química } \\
\text { Ambiental }\end{array}$ & & $\mathbf{X}$ & & \\
\hline $\begin{array}{l}\text { Cangemi, } \\
\text { Santos e Neto } \\
(2010)\end{array}$ & Mamona & $\mathbf{X}$ & & $\mathbf{X}$ & \\
\hline $\begin{array}{l}\text { Filho e } \\
\text { Antedomenico } \\
(2010)\end{array}$ & $\begin{array}{c}\text { Perícia } \\
\text { Criminal }\end{array}$ & $\mathbf{X}$ & & $\mathbf{X}$ & \\
\hline $\begin{array}{l}\text { Texeira, } \\
\text { Bueno e } \\
\text { Cortés (2010) }\end{array}$ & $\begin{array}{l}\text { Biofilme } \\
\text { Dentário }\end{array}$ & $\mathbf{X}$ & & & \\
\hline $\begin{array}{l}\text { Pacheco e } \\
\text { Damasio } \\
(2010)\end{array}$ & Vanilina & $\mathbf{X}$ & & $\mathbf{X}$ & \\
\hline $\begin{array}{l}\text { Silva, Beneti e } \\
\text { Soares (2011) }\end{array}$ & $\begin{array}{l}\text { Sistema } \\
\text { olfativo }\end{array}$ & $\mathbf{X}$ & $\mathbf{X}$ & $\mathbf{X}$ & \\
\hline $\begin{array}{l}\text { Venquiaruto, } \\
\text { Dallago, } \\
\text { Vanzeto e } \\
\text { Pino (2011) }\end{array}$ & Pão & $\mathbf{X}$ & $\mathbf{X}$ & $\mathbf{X}$ & \\
\hline $\begin{array}{l}\text { Rebello, } \\
\text { Argyros, Leie, } \\
\text { Santos, Barro, } \\
\text { Santos e Silva } \\
(2012)\end{array}$ & Nanotecnologia & $\mathbf{X}$ & $\mathbf{X}$ & & \\
\hline $\begin{array}{l}\text { Albuquerque, } \\
\text { Santos, } \\
\text { Cerqueira e } \\
\text { Silva (2012) }\end{array}$ & $\begin{array}{c}\text { Aditivos } \\
\text { alimentares }\end{array}$ & & $\mathbf{X}$ & & \\
\hline Morioko e & Penhora & $\mathbf{X}$ & & $\mathbf{X}$ & $\mathbf{X}$ \\
\hline
\end{tabular}




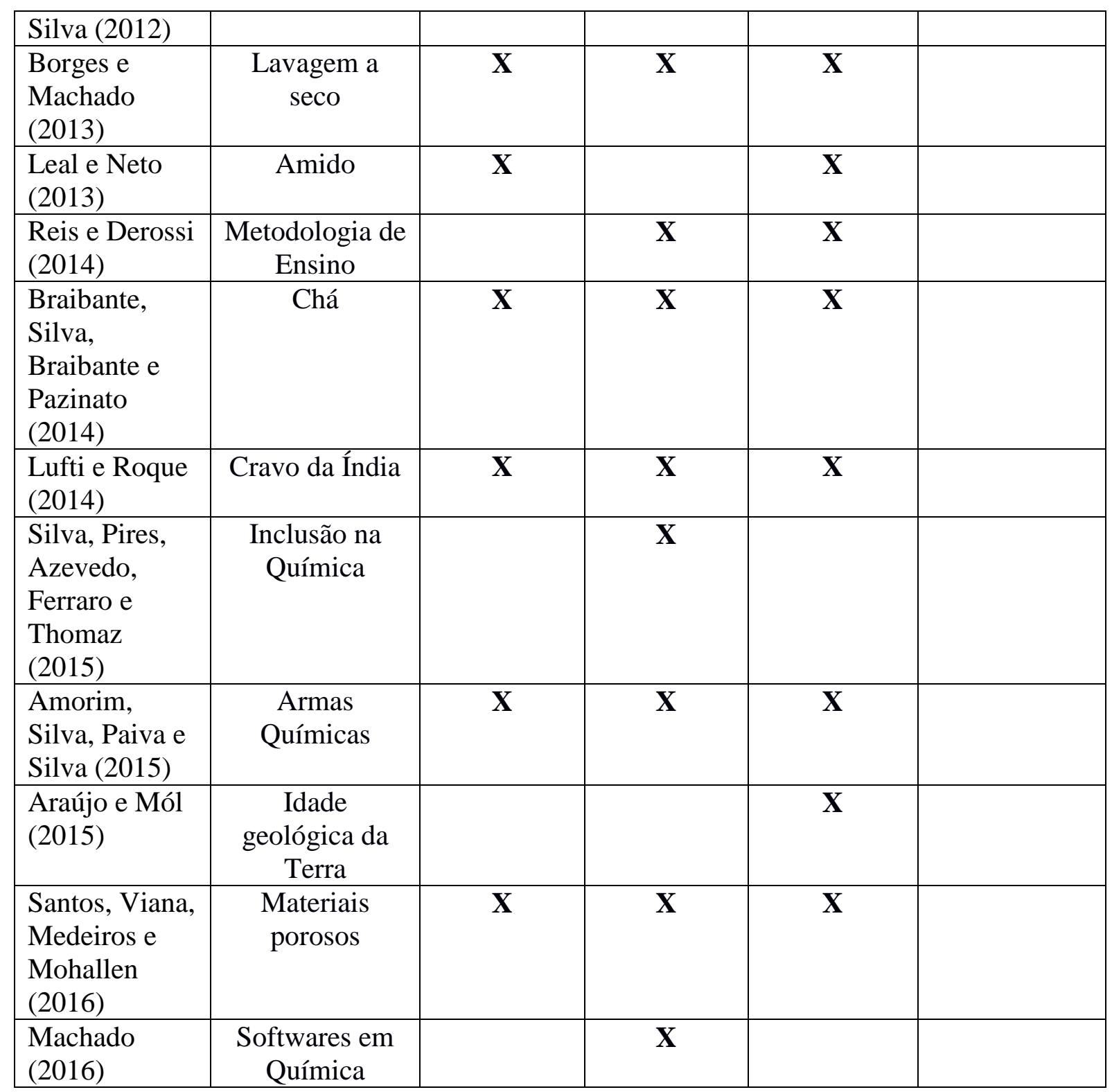

\section{Competência para Alfabetização Científica Prática}

Foi evidenciado a partir das análises, uma tendência natural dos autores relacionado a alfabetização cientifica prática, pode-se constatar muito claramente esta finalidade em praticamente todos os artigos. A explicação de um determinado processo corriqueiro no dia-adia do indivíduo foi bastante explorada pelos autores como o processo de obtenção da mamona, síntese dos poliuretanos, obtenção da vanilina, produção de tênis, parâmetros avaliativos da qualidade das águas naturais, processo de lavagem a seco, obtenção do pão, obtenção da goma e produção de produtos de amido. Os conteúdos necessários de Química para a compreensão podemos expor as funções e reações orgânicas, ácidos e bases, pH e soluções.

Parte dos artigos os autores buscaram introduzir o funcionamento ou procedimento para determinados eventos comumente observados como procedimentos da perícia criminal, 
funcionamento do gás lacrimogêneo, captação de odores e utilização do cravo da índia. Nesse sentido os conteúdos necessários foram ligações químicas, gases ideais, densidade e outros conteúdos das ciências de física e biologia.

Podemos classificar os artigos analisados como satisfatórios no âmbito da alfabetização científica prática, onde o leitor pode compreender de forma clara e objetiva alguns fenômenos e procedimentos habituais de seu cotidiano, desenvolvendo um cidadão ativo e pensante na sociedade onde vive, sendo capaz de explicar de maneira consciente os acontecimentos vivenciados.

\section{Competência para Alfabetização Científica Cívica}

Neste aspecto os autores visam uma abordagem crítica, onde o leitor deve relacionar o conteúdo estudado com seu posicionamento a respeito, ou seja, tomar decisões racionais sobre determinados processos e procedimentos. Nos artigos percebeu-se esta perspectiva intimamente ligada a alfabetização científica prática, houve um elo entre apresentar um determinado fenômeno e como refletir criticamente sobre o mesmo.

Desta forma, os artigos destacaram questões como o uso adequado dos softwares educacionais, qual forma ideal para utilização do cravo da índia, distinção acerca dos tipos de chá, o uso correto dos lacrimogêneos, identificar os diversos tipos de tênis e suas especificidades, como reconhecer a qualidade das águas naturais a partir de seus parâmetros físico-químicos, evitar de forma eficiente a formação de cáries, qual temperatura necessária para fermentação do pão e reflexão sobre os problemas ambientais acerca dos polímeros. Destaca-se principalmente nos artigos analisados a importância de uma conscientização efetiva sobre os temas propostos, inserindo uma proposta reflexiva, indagadora e critica, colocando o indivíduo como protagonista de suas atitudes frente aos acontecimentos vividos.

\section{Competência para Alfabetização Científica Cultural}

No que diz respeito a esta finalidade, encontramos poucos artigos que de fato procuraram inserir em seu corpo este aspecto, foram apresentados um contexto histórico acerca da origem do dinheiro, a utilização da vanilina do século XVIII, primeiros registros no preparo do pão, os materiais porosos e a evolução do homem, conflito entre ciência e religião em relação a idade da terra, realização da colheita do cravo da índia na antiguidade, primeiras referências escritas sobre o chá, a utilização do gás lacrimogêneo nas guerras, a produção de calçados no tempo das cavernas.

Nesse sentido, os autores fizeram uma retrospectiva sobre o tema levando a concepção atual e as evoluções que ocorreram ao longo do tempo.

É fundamental para o desenvolvimento do cidadão, o conhecimento dos aspectos 
históricos e curiosidades acerca dos conteúdos estudados, para haver uma maior compreensão do processo, funcionamento ou procedimento, na perspectiva de desenvolvimento, onde muitas vezes, o indivíduo precisa entender o passado para refletir e agir sobre determinados eventos do presente e futuro.

\section{Competência para Alfabetização Científica Profissional/Econômica}

Nesta competência foi evidenciado apenas um trabalho que aborda esta finalidade, onde introduz as técnicas utilizadas profissionalmente na produção de ligas metálicas e levanta dados sobre o mercado monetário dos metais e rentabilidade. De fato, esta competência é bastante escassa nos artigos de modo geral, sabemos que a alfabetização cientifica está em um processo de habitação entre os estudiosos e os trabalhos realizados apresentam uma maior afinidade para a alfabetização científica prática, cívica e cultural.

\section{Conclusões}

A alfabetização científica não tem como finalidade a formação de cientistas, e sim, em colaborar no desenvolvimento social por meio da conscientização da população acerca do conhecimento científico, importante na resolução de problemas e discussões através de temas comuns no cotidiano.

Portanto, os trabalhos analisados trazem de maneira clara e objetiva uma perspectiva inovadora para o desenvolvimento do elo entre ciências e sociedade, destacando temas corriqueiros no dia-a-dia para explicar determinado fenômeno, procedimento e processo levando o indivíduo a um estágio de entendimento e reflexão no âmbito das experiências vividas diariamente.

\section{Referências}

ALBUQUERQUE, M. V.; SANTOS, S. A.; CERQUEIRA, N. T. V.; SILVA, J. A. Educação Alimentar: Uma Proposta de Redução do Consumo de Aditivos Alimentares. QNESC, n. 2, v. 34, p. 51-57, 2012.

AMORIM, N. M.; SILVA, R. A.; PAIVA, D. V. M.; SILVA, M. G. V. Química e Armas Não Letais: Gás Lacrimogêneo em Foco. QNESC, n. 2, v. 37, p. 88-92, 2015.

ARAÚJO, D. F.; MÓL, G. S. A. Radioquímica e a Idade da Terra. QNESC, n. 3, v. 37, p. 164$171,2015$.

BISPO, D. DE O.; M.D. MACIEL; R.P. SEPINI e A.V. ALONSO. Alfabetização científica sob o enfoque da ciência, tecnologia e sociedade: implicações para a formação inicial e continuada de professores. Revista Electrónica de Enseñanza de las Ciencias, vol. 12, nº 2, 2013. 
BORGES, L. D.; MACHADO, P. F. L. Lavagem a seco. QNESC, n. 1, v. 35, p. 11-18, 2013.

BRAIBANTE, M. E. F.; SILVA, D.; BRAIBANTE, H. T. S.; PAZINATO, M. S. A Química dos Chás. QNESC, n. 3, v. 36, p. 1-8, 2014.

CANGEMI, J, M.; SANTOS, A. M.; NETO, S. C. A Revolução Verde da Mamona. QNESC, n. 1, v. 32, p. 3-8, 2010.

CANGEMI, J, M.; SANTOS, A. M.; NETO, S. C. Poliuretano: De Travesseiros a Preservativos, um Polímero Versátil. QNESC, n. 3, v. 31, p. 159-164, 2009.

CHASSOT, A. Scientific literacy: a possibility for social inclusion. Revista Brasileira de Educação. Jan./Apr. no.22, p.89-100, 2003.

FILHO, C. R. D.; ANTEDOMENICO, E. A Perícia Criminal e a Interdisciplinaridade no Ensino de Ciências Naturais. QNESC, n. 2, v. 32, p. 67-72, 2010.

FOUREZ, G.; ENGLEBERT-LECOMPTE, V.; GROOTAERS, D.; MATHY, P.; TILMAN, F. Alfabetización científica y tecnológica: Acerca de las Finalidades de la Enseñanza de las Ciencias, $1^{\circ}$ edição. Buenos Aires: Colihue, 2005. p. 121-127.

FREIRE, Paulo. Educação como prática da liberdade. $10^{\mathrm{a}}$ ed. Rio de Janeiro: Paz e Terra, 1980.

FURIÓ, C.; VILVHES, A.; GUISASOLA, J.; ROMO, V. Finalidades de La Enseñanza de Lãs Ciências em La Secundaria Obligatoria. Enseñanza de lãs Ciências, v. 19, n³, p. 365-376, 2001.

HURD, P. D. Scientific Literacy: new minds for a changing world, Science Education, v. 82, n. 3, 407-416, 1998.

LEAL, R. C.; NETO, J. M. M. Amido: Entre a Ciência e a Cultura. QNESC, n. 2, v. 35, p. 75 $78,2013$.

LORENZETTI, L.; DELIZOICOV, D. A alfabetização Científica no contexto das séries iniciais. Revista Ensaio - Pesquisa em Educação em Ciências, v.3, n.1, p. 37-50, março, 2001.

LUFTI, M.; ROQUE, N. F. Histórias de Eugênias. QNESC, n. 4, v. 36, p. 1-9, 2014.

MACHADO, A. S.; Uso de Softwares Educacionais, Objetos de Aprendizagem e Simulações no Ensino de Química. QNESC, n. 2, v. 38, p. 104-111, 2016.

MATHEUS, A. L. M. L.; MACHADO, A. H.; BRASILEIRO, L. B. Articulação de Conceitos Químicos em Um Contexto Ambiental por Meio do Estudo do Ciclo de Vida de Produtos. QNESC, n. 4, v. 31, p. 231-234, 2009.

MILARÉ, T.; RICHETTI, G. P. Alfabetização Científica no Ensino de Química: um olhar sobre os temas sociais. In: XIV Encontro Nacional de Ensino de Química (XIV ENEQ) UFPR. Curitiba/PR., 2008.

MORIOKO, R. M.; SILVA, R. R. A Atividade de Penhor e a Química. QNESC, n. 3, v. 34, p. 111-117, 2012. 
PACHECO, S. M. V.; DAMASIO, F. Vanilina: Origem, Propriedades e Produção. QNESC, n. 4, v. 32, p. 215-219, 2010.

REBELlO, G. A. F.; ARGYROS, M. M.; LEIE, L. L.; SANTOS, M. M.; BARROS, J. C.; SANTOS, P. M. L.; SILVA, J. F. M. Nanotecnologia, um tema para o ensino médio utilizando a abordagem CTSA. QNESC, n. 1, v. 34, p. 3-9, 2012.

REIS, I. F.; DEROSSI, I. N. O Ensino de Ciências por Marie Curie: Análise da Metodologia Empregada em sua Primeira Aula na Cooperativa de Ensino. QNESC, n. 2, v. 36, p. 88-92, 2014.

SANTOS, A. S.; SILVA, G. G. O Tênis Nosso de Cada Dia. QNESC, n. 2, v. 31, p. 67-75, 2009.

SANTOS, A. V.; VIANA, M. M.; MEDEIROS, F. H. A.; MOHALLEN, D. S. O Incrível Mundo dos Materiais Porosos - Características, Propriedades e Aplicações. QNESC, n. 1, v. 38, p. 4$11,2016$.

SASSERON, L. H.; CARVALHO, A. M. P. Alfabetização científica: uma revisão bibliográfica. Revista Investigação em Ensino de Ciências, Rio Grande do Sul, v. 16, p. 59-77, 2011.

SASSERON, L. H.; CARVALHO, A. M. P. Almejando a alfabetização científica no ensino fundamental: a proposição e a procura de indicadores do processo. Revista Investigações em Ensino de Ciências, Porto Alegre, v. 13, n. 3, p. 333-352, 2008.

SHEN, B. S. P. Science Literacy. American Scientist, Durham, v. 63, p. 265 - 268, 2004.

SILVA, R.; PIRES, M. J. R.; AZEVEDO, C. M. N.; FERRARO, C. S.; THOMAZ, E. Kit Experimental para Análise de CO2 Visando à Inclusão de Deficientes Visuais. QNESC, n. 1, v. 37, p. 4-10, 2015.

SILVA, V. A.; BENETI, M. C.; SOARES, M. H. F. B. Algo Aqui Não Cheira Bem... A Química do Mau Cheiro. QNESC, n. 1, v. 33, p. 3-9, 2011.

SOARES, M. B. Um olhar sobre o livro didático. Revista Presença Pedagógica, Belo Horizonte, v. 2, n. 12, p. 53-59, 1996.

TAKAHASHI, J. A.; MARTINS, P. F. F.; QUADROS, A. L. Questões Tecnológicas Permeando o Ensino de Química: O Caso dos Transgênicos. QNESC, n. 1, v. 29, p. 3-7, 2008.

TEXEIRA, K. I. R.; BUENO, A. C.; CORTÉS, M. E. Processos Físico-Químicos no Biofilme Dentário Relacionados à Produção da Cárie. QNESC, n. 3, v. 32, p. 145-150, 2010.

VENQUiARUTO, L. D.; DALlAGO, R. M.; VANZETO, J.; PINO, J. C. Saberes Populares Fazendo-se Saberes Escolares: Um Estudo Envolvendo a Produção Artesanal do Pão. QNESC, n. 3, v. 33, p. 135-141, 2011.

VIECHENESKI, J. P; CARLETTO, M.R. Ensino de Ciências e Alfabetização Científica nos anos iniciais do Ensino Fundamental: um olhar sobre as escolas públicas de Carambeí. In: VIII Encontro Nacional de Pesquisa em Educação em Ciências, 2011, Campinas/SP. Anais. 
Disponível em:http://www.nutes.ufrj.br/abrapec/viiienpec/resumos/R0741-1.pdf. Acesso em: 16 de set. 2016.

ZUIN, V. G.; LORIATTI, M. C. S.; MATHEUS, C. E. O Emprego de Parâmetros Físicos e Químicos para a Avaliação da Qualidade de Águas Naturais: Uma Proposta para a Educação Química e Ambiental na Perspectiva. CTSA. QNESC, n. 1, v. 31, p. 3-8, 2009. 